Götz Thomalla, MD

Florent Boutitie, $\mathrm{PhD}$

Jochen B. Fiebach, MD

Claus Z. Simonsen, MD, $\mathrm{PhD}$

Norbert Nighoghossian, MD

Salvador Pedraza, MD

Robin Lemmens, MD

Pascal Roy, MD

Keith W. Muir, MD

Christoph Heesen, MD

Martin Ebinger, MD

Ian Ford, PhD

Bastian Cheng, MD

Tae-Hee Cho, MD

Josep Puig, MD

Vincent Thijs, MD

Matthias Endres, MD

Jens Fiehler, MD

Christian Gerloff, MD

Correspondence to

Dr. Thomalla:

thomalla@uke.de

\title{
Effect of informed consent on patient characteristics in a stroke thrombolysis trial OPEN
}

\section{ABSTRACT}

Objective: To determine whether the manner of consent, i.e., informed consent by patients themselves or informed consent by proxy, affects clinical characteristics of samples of acute stroke patients enrolled in clinical trials.

Methods: We analyzed the manner of obtaining informed consent in the first 1,005 patients from WAKE-UP, an investigator-initiated, randomized, placebo-controlled trial of MRI-based thrombolysis in stroke patients with unknown time of symptom onset running in 6 European countries. Patients providing informed consent by themselves were compared with patients enrolled by proxy consent. Baseline clinical measures were compared between groups.

Results: In 359 (35.7\%) patients, informed consent was by proxy. Patients with proxy consent were older (median 71 vs 66 years, $p<0.0001$ ) and had a higher frequency of arterial hypertension (58.2\% vs 43.4\%, $p<0.0001)$. They showed higher scores on the NIH Stroke Scale (median 11 vs $5, p<0.0001$ ) and more frequently aphasia (73.7\% vs $20.0 \%, p<0.0001)$. The rate of proxy consent varied among countries $(p<0.0001)$, ranging from $77.1 \%$ in Spain to $1.2 \%$ in Denmark.

Conclusions: Patients recruited by proxy consent were older, had more severe strokes, and had higher prevalence of aphasia than those with capacity to give personal consent. Variations in the manner of consent across countries may influence trial results.

Clinicaltrials.gov and Clinicaltrialsregister.eu identifiers: NCT01525290 (clinicaltrials.gov); 2011-005906-32 (clinicaltrialsregister.eu). Neurology ${ }^{\circledR}$ 2017;89:1400-1407

\section{GLOSSARY}

DWI = diffusion-weighted imaging; FLAIR = fluid-attenuated inversion recovery; IQR = interquartile range; $\mathbf{N I H S S}=\mathrm{NIH}$ Stroke Scale.

As a general principle, any research involving humans requires voluntary participation based on informed consent. ${ }^{1}$ This also applies to enrollment in clinical trials und usually requires participants to give written informed consent after having received detailed information about potential benefits and risks as well as alternative treatment options, and after having had adequate time for consideration. Trials in acute stroke, however, present several challenges to this approach. Reperfusion therapies in acute stroke show a clear time-dependent effect, being more effective the earlier treatment is started, or reperfusion achieved. ${ }^{2,3}$ Both routine care and clinical trials in acute stroke

From Klinik und Poliklinik für Neurologie, Kopf- und Neurozentrum (G.T., C.H., B.C., C.G.), and Klinik und Poliklinik für Neuroradiologische Diagnostik und Intervention, Diagnostikzentrum (J.F.), Universitätsklinikum Hamburg-Eppendorf, Hamburg, Germany; Service de Biostatistique (F.B., P.R.) and Department of Neurology (N.N., T.-H.C.), Hospices Civils de Lyon; Université Lyon 1 (F.B., P.R.), Villeurbanne; CNRS, UMR 5558 (F.B., P.R.), Laboratoire de Biométrie et Biologie Evolutive, Equipe Biostatistique-Santé, Villeurbanne, France; Centrum für Schlaganfallforschung Berlin (CSB) (J.B.F., M. Ebinger, M. Endres) and Klinik und Hochschulambulanz für Neurologie (M. Ebinger, M. Endres), CharitéUniversitätsmedizin Berlin, Germany; Department of Neurology (C.Z.S.), Aarhus University Hospital, Denmark; Department of Radiology (S.P., J.P.), Institut de Diagnostic per la Image (IDI), Hospital Dr Josep Trueta, Institut d'Investgació Biomèdica de Girona (IDIBGI), Girona, Spain; Department of Neurosciences, Experimental Neurology, and Leuven Research Institute for Neuroscience and Disease (LIND) (R.L.), KU LeuvenUniversity of Leuven; VIB, Laboratory of Neurobiology (R.L.), Center for Brain \& Disease Research, Leuven; Department of Neurology (R.L.), University Hospitals Leuven, Belgium; Institute of Neuroscience \& Psychology (K.W.M.) and Robertson Centre for Biostatistics (I.F.), University of Glasgow, UK; Stroke Division (V.T.), Florey Institute of Neuroscience and Mental Health; and Department of Neurology (V.T.), Austin Health, Heidelberg, Australia.

Go to Neurology.org for full disclosures. Funding information and disclosures deemed relevant by the authors, if any, are provided at the end of the article. The Article Processing Charge was funded by the European Commission.

This is an open access article distributed under the terms of the Creative Commons Attribution-NonCommercial-NoDerivatives License 4.0 (CC BY-NC-ND), which permits downloading and sharing the work provided it is properly cited. The work cannot be changed in any way or used commercially without permission from the journal. 
are carried out under pressure of time. Thus, time available for consideration is very short. In addition, the brain injury commonly compromises language function, awareness of neurologic deficits, conscious level, and physical abilities, including vision and writing, relevant to the usual consent process. Since most stroke patients lack capacity to provide consent, ${ }^{4,5}$ alternative approaches are needed, ${ }^{6,7}$ and the bias introduced by systematic exclusion of certain subgroups of stroke patients, e.g., those with aphasia, has been reviewed critically. ${ }^{8}$

Previous stroke trials point towards possible meaningful differences between patients able to give consent by themselves and those enrolled by proxy consent, with patients enrolled by proxy consent being more severely affected. ${ }^{9,10}$ However, the number of studies addressing this research question is small, and it is uncertain how the manner of obtaining consent affects further characteristics of stroke patients enrolled in clinical trials and how this might affect the generalizability of trial results. To address this question, we analyzed data of the first 1,005 patients enrolled in WAKE-UP, a European multicenter randomized controlled clinical trial of IV thrombolysis in acute stroke patients with unknown time of symptom onset based on MRI. ${ }^{11}$ We study the effect of the manner of consent on the clinical characteristics of patients enrolled. Moreover, we also describe national variations in the manner of obtaining informed consent, an issue that has not yet been studied for acute stroke trials.

METHODS Study population. WAKE-UP (Efficacy and safety of MRI-based thrombolysis in wake-up stroke: a randomised, double-blind, placebo-controlled trial) is an investigatorinitiated, randomized, double-blind, placebo-controlled trial designed to test the efficacy and safety of IV thrombolysis in patients with unknown time of symptom onset selected by MRI. ${ }^{11}$ Patients are screened with MRI including diffusionweighted imaging (DWI) and fluid-attenuated inversion recovery (FLAIR), and the presence of a DWI-FLAIR mismatch indicating ischemic stroke lesion $<4.5$ hours $^{12}$ represents the main imaging criterion for randomization to treatment with either IV tissue plasminogen activator or placebo. The trial was started in September 2012. The present analysis includes baseline data of patients enrolled until April 1, 2016. Only information recorded at baseline was analyzed, and only data of patients with at least information concerning informed consent, symptom onset, age, and sex were included.

Standard protocol approvals, registrations, and patien consents. WAKE-UP was approved by the national competent authorities and ethics committees in all participating countries.
WAKE-UP was registered at clinicaltrials.gov (NCT01525290) and clinicaltrialsregister.eu (2011-005906-32).

Informed consent has to be obtained prior to enrollment of patients in the trial. Options for proxy consent are given in accordance with the following European and national regulations (figure 1):

A: The patient is judged to have capacity to give informed consent and able to provide written consent: the patient provides written consent.

B: The patient is judged to have capacity to give informed consent but unable to provide written consent due to a physical barrier: the patient provides witnessed oral consent and provides later written consent as soon as possible.

C: The patient lacks capacity to give informed consent, legal guardian is available: the legal guardian acts on behalf of the patient and provides written consent.

D: The patient lacks capacity to give informed consent, legal guardian is not available, informed consent by next of kin: next acts on behalf of the patient following the patient's presumed will and provides written consent; patient or legal guardian provides later written consent as soon as possible.

E: The patient lacks capacity to give informed consent, legal guardian is not available, enrollment of patient by consensus between investigator and independent physician: the patient may be enrolled by consensus between the investigator and an independent physician; if possible, patient's next of kin should be contacted to appraise the patient's presumed will; the patient or legal guardian provides later written consent as soon as possible.

F: The patient lacks capacity to give informed consent, legal guardian is not available, enrollment of patient by investigator: the patient may be enrolled by the investigator acting on behalf of the patient following the patient's presumed will; if possible, the patient's next of kin should be contacted to appraise the patient's presumed will; the patient or legal guardian provides later written consent as soon as possible.

Clinical examinations and MRI at baseline. Neurologic examination was performed by certified investigators using the NIH Stroke Scale (NIHSS).$^{13}$ Information on time of symptom recognition and of the time point last seen well was obtained from patients or caregivers, and the reason why exact symptom onset was unknown was recorded according to 5 categories: night sleep, day sleep, unwitnessed stroke with aphasia, unwitnessed stroke with confusion, other. Time of admission to hospital was obtained from the medical records.

MRI including DWI and FLAIR was performed according to the trial protocol. Local investigators judged DWI-FLAIR mismatch according to standards provided together with the study protocol and after completion of a computer-based image judgement training and certification. Presence of a visible acute ischemic lesion on DWI, DWI-FLAIR mismatch, and any signs of intracranial haemorrhage were recorded.

Statistical analysis. Demographic and clinical characteristics as well as imaging findings at baseline are described and compared between groups. The following delays were calculated: time between last seen well and symptom recognition, time between symptom recognition and hospital admission, time between hospital admission and informed consent, and time between hospital admission and administration of the study drug. In addition to the NIHSS sum score, presence of aphasia as assessed by item 9 of the NIHSS and disturbance of level of consciousness as assessed by item 1a of the NIHSS were analyzed separately as categorical variables.

Descriptive statistics are provided including median (interquartile range $[\mathrm{IQR}]$ ) and percentages for continuous and categorical data, respectively. For group comparison, the manner of informed 


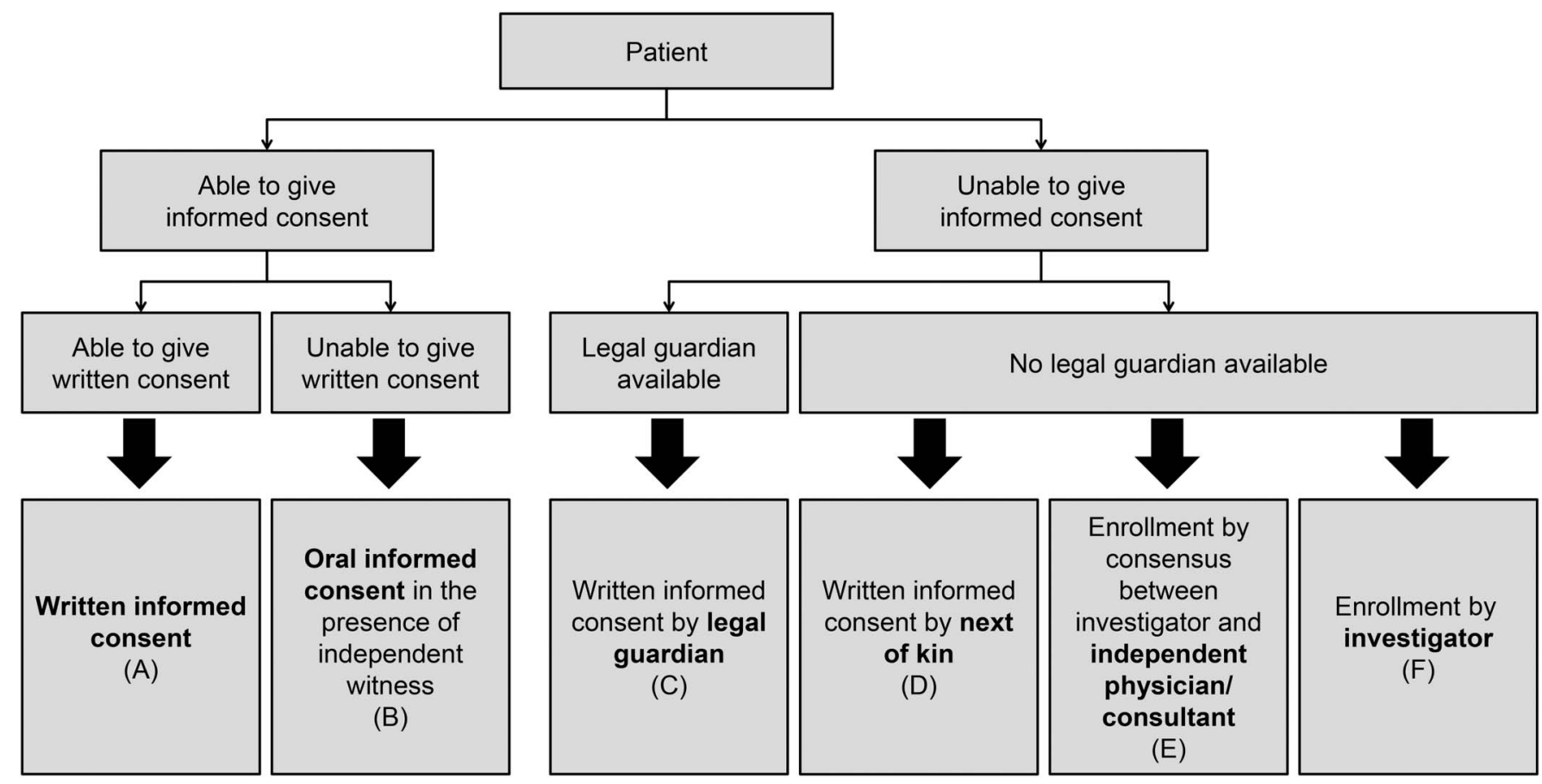

The different means of obtaining informed consent in WAKE-UP depending on the ability of the patient to give informed consent and on the availability of a legal guardian. The means of informed consent allowed for patient enrollment differed by country according to national regulations and the approval of national and regional ethics committees.

consent was dichotomized into informed consent by the patient personally (written or oral: A, B) or informed consent by proxy (legal guardian, next of kin, consultant, or investigator: C, D, E, F). The manner of obtaining informed consent was also compared among countries for the 6 countries enrolling patients at the time of database export (Belgium, Denmark, France, Germany, Spain, United Kingdom). Fisher exact test or $\chi^{2}$ test was used to compare groups for categorical variables, and the Kruskal-Wallis test was used for continuous variables. In order to account for heterogeneity among countries, group comparisons were repeated by fitting a logistic regression model of the odds of informed consent given by proxy according to each factor adjusted for country. All analyses are considered exploratory. SAS software, version 9.3 (SAS Institute Inc., Cary, NC) was used for all analyses.

RESULTS Of 1,039 patients enrolled in the trial, 1,005 patients met the inclusion criteria and were included in the analysis. Median age was 68 years
(IQR 58-75 years); 38.8\% of patients were women. In 646 (64.3\%) patients, informed consent was given by the patients themselves, while in 359 (35.7\%), informed consent was by proxy (see table 1 for distribution of means of informed consent).

Patients enrolled via informed consent by proxy were older (median 71 vs 66 years, $p<0.0001$ ) and were more frequently female $(49.9 \%$ vs $32.7 \%$, $p<0.0001$; table 2). They also had a longer delay between the time point last seen normal and the time of symptom recognition (8.9 vs 7.3 hours, $p<$ $0.0001)$. In contrast, the delay between symptom recognition and hospital arrival was shorter (1.5 vs 1 hour, $p<0.0001)$. Regarding trial-related activities, the delays between hospital admission and informed consent and between admission to hospital

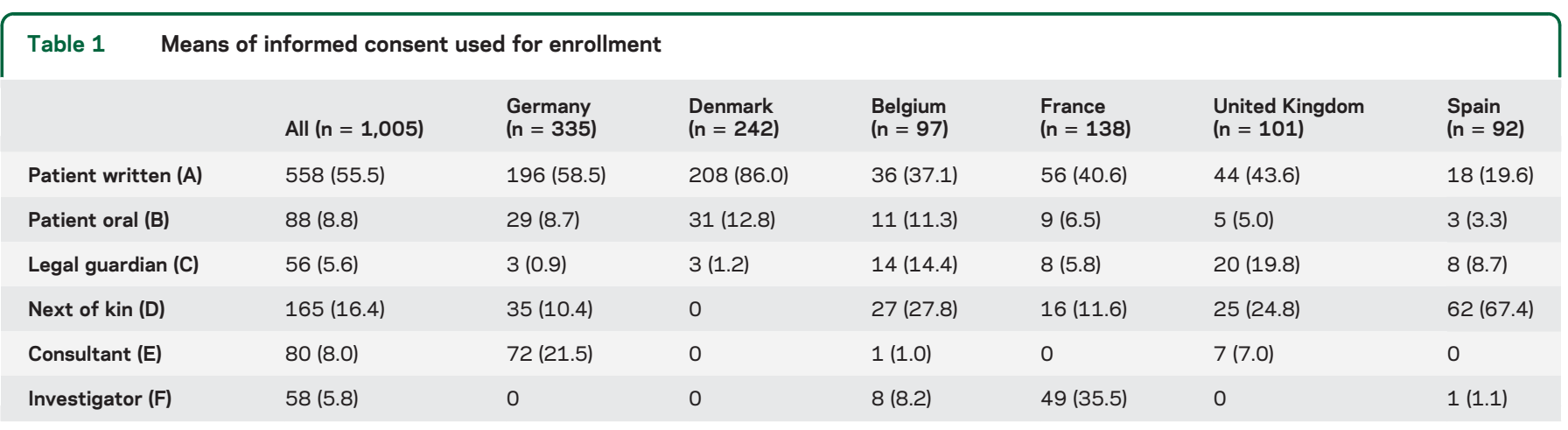

All values $\mathrm{n}(\%)$; the distribution of means of informed consent was significantly different by country $\left(\mathrm{p}<0.0001, \chi^{2}\right.$ test). 
Table 2 Clinical characteristics by means of informed consent

\begin{tabular}{|c|c|c|c|c|}
\hline & $\begin{array}{l}\text { Informed consent by } \\
\text { patient ( } n=646)\end{array}$ & $\begin{array}{l}\text { Informed consent by } \\
\text { proxy ( } \mathrm{n}=359)\end{array}$ & $\begin{array}{l}\text { Group comparison } \\
\text { p value (unadjusted) }\end{array}$ & $\begin{array}{l}\text { Group comparison } \\
\text { p value (adjusted } \\
\text { for country) }\end{array}$ \\
\hline Age, y, median (IQR) & $66(56-73)$ & 71 (62-76) & $<0.0001$ & $<0.0001$ \\
\hline $\begin{array}{l}\text { Delay between last seen well and symptom } \\
\text { recognition, h, median (IQR) [n] }\end{array}$ & $7.3(5.0-8.8)[593]^{\mathrm{b}}$ & $8.9(6.5-11.0)[290]^{\mathrm{b}}$ & $<0.0001$ & $<0.0001$ \\
\hline $\begin{array}{l}\text { Delay between admission to hospital and } \\
\text { informed consent, } h \text {, median (IQR) [n] }\end{array}$ & $0.33(0.17-0.75)[611]^{\mathrm{b}}$ & $0.56(0.30-0.93)[332]^{b}$ & $<0.0001$ & 0.99 \\
\hline $\begin{array}{l}\text { Delay between admission to hospital and } \\
\text { IMP administration, } h \text {, median (IQR) [n] }\end{array}$ & $1.20(0.92-1.52)[247]^{b}$ & $1.54(1.17-1.90)[110]^{\mathrm{b}}$ & $<0.0001$ & 0.41 \\
\hline \multicolumn{5}{|l|}{ Medical history/risk factors, ${ }^{b} \mathrm{n}(\%)$} \\
\hline Atrial fibrillation & $38 / 614(6.2)$ & $36 / 345$ (10.4) & 0.018 & 0.24 \\
\hline Ischemic stroke & $75 / 624$ (12.0) & $45 / 349$ (12.9) & 0.69 & 0.81 \\
\hline TIA & 32/621 (5.2) & $14 / 346(4.1)$ & 0.44 & 0.11 \\
\hline Intracranial haemorrhage & $1 / 625$ (0.2) & $1 / 346(0.3)$ & 0.67 & 0.22 \\
\hline Gastrointestinal bleeding & 12/623 (1.9) & $3 / 350(0.9)$ & 0.19 & 0.033 \\
\hline NIHSS on admission, median (IQR) & $5(3-7)$ & $11(7-17)$ & $<0.0001$ & $<0.0001$ \\
\hline Aphasia, n (\%) & $128 / 639(20.0)$ & $264 / 358(73.7)$ & $<0.0001$ & $<0.0001$ \\
\hline $\begin{array}{l}\text { Disturbed level of consciousness (NIHSS } \\
\text { LOC item } 1 \mathrm{a}>1), \mathrm{n}(\%)\end{array}$ & 22/639 (3.4) & $61 / 358(17)$ & $<0.0001$ & $<0.0001$ \\
\hline
\end{tabular}

Abbreviations: DWI = diffusion-weighted imaging; FLAIR = fluid-attenuated inversion recovery; IQR = interquartile range; LOC = level of consciousness; NIHSS $=$ NIH Stroke Scale.

a Result of logistic regression analysis adjusted for country.

${ }^{b}$ Data calculated for number of patients with information available given in parentheses.

${ }^{\mathrm{c}}$ Intracerebral hemorrhage, subarachnoid haemorrhage, intraventricular haemorrhage, hemorrhagic transformation.

and the start of study drug, respectively, were longer for patients with informed consent by proxy, but in the additional analysis adjusted for country, no significant association was found.

Arterial hypertension was observed more frequently in patients with informed consent by proxy $(58.2 \%$ vs $43.4 \%, p=0.0022)$. Diabetes mellitus, hypercholesterolemia, and atrial fibrillation also were observed more frequently in patients with proxy consent, but the difference was not significant after adjustment for country. Patients enrolled via informed consent by proxy presented with a more severe neurologic deficit on admission, reflected by higher values on the NIHSS (median 11 vs $5, p<$ 0.0001 ). They also showed more frequently aphasia (73.7\% vs $20.0 \%, p<0.0001)$ and disturbed level of consciousness $(17.0 \%$ vs $3.4 \%, p<0.0001)$. Of note, MRI findings (i.e., findings of intracranial haemorrhage, acute DWI lesions, and DWI-FLAIR mismatch) did not differ between groups.

The relative frequency of the manner of informed consent used for enrollment varied among countries $(p<0.001$; table 1$)$. Written consent by patients themselves was the most frequent manner of informed consent in all countries apart from Spain (ranging from $86.0 \%$ in Denmark to $19.6 \%$ in Spain). Informed consent by next of kin ranged from $67.4 \%$ in Spain to not being used at all in Denmark. Enrollment by independent physician was used in $21.2 \%$ of cases in Germany but was only rarely used in other countries. In contrast, enrollment by investigator was common in France (35.5\%), less frequent in Belgium (8.2\%), but only used in single cases in the other countries. Overall, the proportion of 


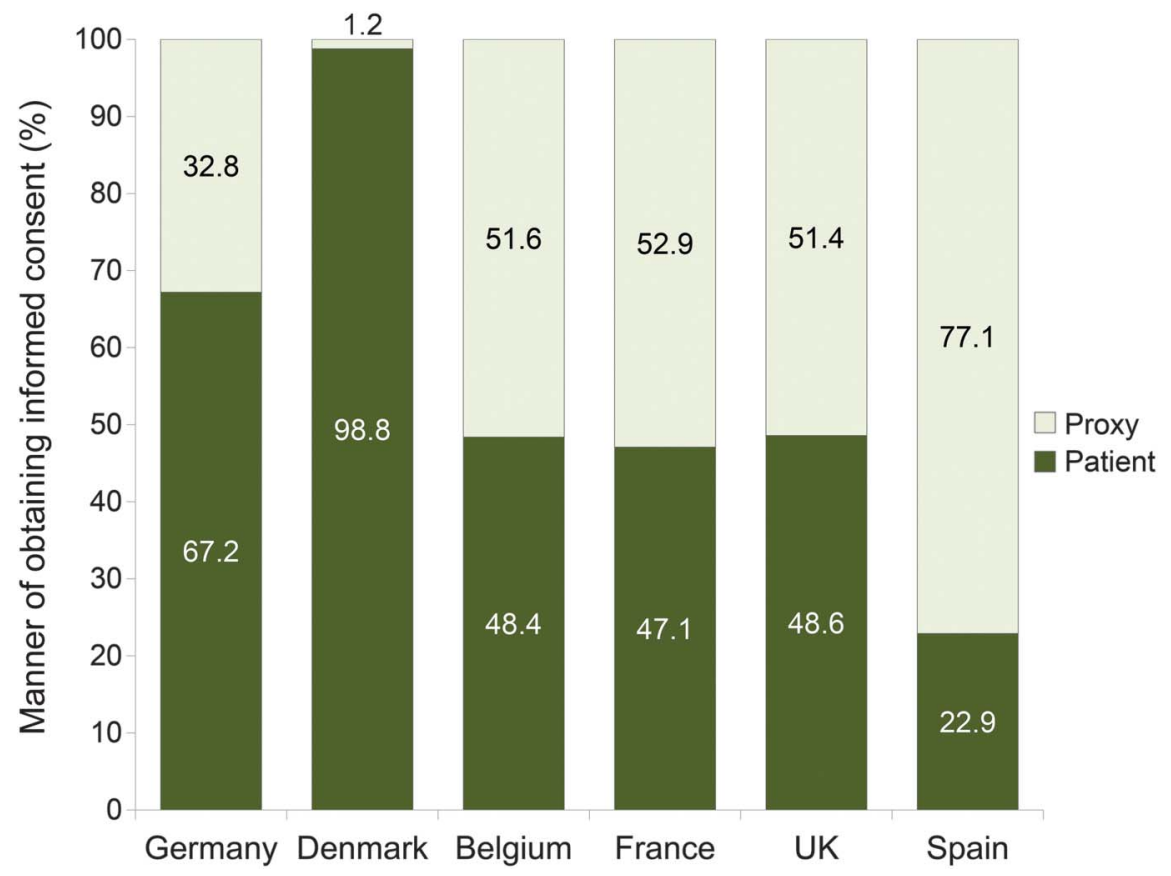

The distribution of the different means of informed consent obtained in WAKE-UP, i.e., either by patients themselves or by proxy, for the 6 countries participating in the trial at the time of database extraction for the current analysis.

informed consent by proxy ranged from $77.1 \%$ in Spain to $1.2 \%$ in Denmark (figure 2).

DISCUSSION In this analysis of baseline data of the first 1,005 patients enrolled in the WAKE-UP trial, about 1 in 3 patients were enrolled by proxy consent. In these cases, consent was provided by the legal guardian, by next of kin, by an independent consultant, or by the investigator based on an emergency clause. There were marked differences in clinical characteristics between patients depending on how informed consent was obtained. Patients enrolled by proxy consent were older, more frequently hypertensive, and had more severe stroke symptoms reflected by higher NIHSS scores. Patients enrolled by proxy consent were also about 3.5 times more likely to be aphasic and 5 times more likely to have a disturbed level of consciousness. These observations are consistent with previous observations. ${ }^{4,8}$ Both prestroke conditions (i.e., higher age, more severe comorbidity) and stroke-related factors (i.e., more severe neurologic symptoms including higher rate of aphasia) contribute to lack of capacity to give informed consent.

Our findings are consistent with observations from 2 other trials of IV thrombolysis. In the National Institute of Neurological Disorders and Stroke trial, 439 of 624 (70\%) patients were enrolled by proxy consent, and these patients were older and more severely affected. ${ }^{9}$ In the first 300 patients enrolled in the third International Stroke Trial (IST-3), patients with nonlacunar hemispheric stroke syndromes and those with a more severe neurologic deficit were more likely to have been enrolled by proxy consent. ${ }^{10}$ Observations of imaging characteristics have noted smaller DWI volumes and absence of large artery occlusion among patients without capacity to consent. ${ }^{14}$ These results underline that restricting enrollment to patients with capacity for consent will systematically exclude specific subgroups of stroke patients and result in populations that are not representative of acute stroke patients in general. ${ }^{15}$ In a Cochrane review on information provision to stroke patients and caregivers, only 10 of 14 randomized controlled trials included in the review excluded patients with aphasia due to incapacity to consent. ${ }^{16}$ In a single-center interventional stroke trial, inability to consent applied as exclusion criterion to 330 of 1,194 (28\%) patients. ${ }^{17}$ The effects of such restrictions include systematic exclusion of patients with some types of neurologic deficit (e.g., aphasia) from acute stroke research, ${ }^{8}$ loss of generalizability, and slower recruitment rates. Many imaging endpoint biomarkers are likely to be uninformative with such restrictions.

We focused on a comparison of clinical data between patients capable of consent and those not capable without further detailed comparison of the subgroups of patients enrolled with different approaches to proxy consent. However, from an ethics 
perspective, there is a fundamental difference between surrogate consent (category C/D), considered to represent meaningful patient-centered consent, and physician consent in the absence of direct or surrogate consent (category E/F). We performed additional analyses subdividing the group of patients enrolled by proxy consent into patient-centered surrogate consent $(\mathrm{C} / \mathrm{D})$ and physician consent $(\mathrm{E} / \mathrm{F})$. This comparison revealed only slight differences in presenting symptoms, with disturbed level of consciousness and aphasia being slightly more frequent for physician consent $(20.4 \%$ and $79.6 \%)$ as compared to patientcentered surrogate consent (14.9\% and 70.1\%), while age, sex distribution, and median NIHSS were comparable for the 2 subgroups of proxy consent.

Informed consent is considered a fundamental ethical principle of any research involving humans as described in the Declaration of Helsinki. ${ }^{1}$ However, the Declaration of Helsinki also recognizes the problem of obtaining informed consent from patients in critical conditions and suggests different approaches to informed consent. The Food and Drug Administration as well as competent authorities in most European countries allow emergency research without informed consent under strictly defined circumstances. Only limited guidance is provided on how to regulate clinical research in patients incapable of giving informed consent, and as a consequence very different approaches for obtaining informed consent are used in different stroke trials and, within trials, among countries or trial sites. ${ }^{18}$

At the time of database extraction for the current analysis, WAKE-UP was running in 6 European countries: Belgium, Denmark, France, Germany, Spain, and the United Kingdom. In principle, the EU directive on clinical trials (EC) No. 2001/20/ $\mathrm{EC}^{19}$ applies to all of these countries, providing rules for trials in emergency situations. However, the regulations provided in the directive are ambiguous and require interpretation. As a consequence, national regulations and interpretation of these regulations by institutional review boards and ethics committees are implemented with heterogeneous results, leading to a great diversity of national practice with regards to enrollment of incapable patients in Europe. ${ }^{20}$ Within the WAKE-UP trial, we assured that multiple options for informed consent were available. The use of the 5 available approaches differed among the 6 countries. Of note, the proportion of proxy consent varied largely among countries, being hardly used at all in Denmark $(1.2 \%)$ but in more than 2-thirds of patients in Spain (77.1\%). Differences in approval of informed consent for the trial between countries may partly explain this variation (i.e., no approval for proxy consent beyond consent by a legal guardian in Denmark, no approval for consent by investigator in Germany and the United Kingdom). With regards to further reasons for the observed variation, we may only speculate. Differences in the attitude towards and in experience with different manners of informed consent among countries may also play a role. Independent from underlying reasons, these findings may inform the conduct of multinational stroke trials in the future as well as in other disease areas where proxy consent is likely to be used.

Country effects in clinical trials are generally assumed to be largely due to chance and small patient numbers in the individual countries. ${ }^{21}$ However, there may be effects that reflect differences in populations or the clinical setting among countries, resulting in differences in patient characteristics or arguably treatment effect. We observed a confounding effect of country on the association between the manner of informed consent and clinical characteristics that appears plausible in reflecting country-specific aspects of the trial setting. The observed shorter time delay between hospital admission and treatment initiation in patients providing informed consent themselves appeared to be largely driven by a shorter mean delay between hospital admission and treatment initiation in Denmark as compared to all other countries, together with the fact that in Denmark virtually all patients were enrolled based on self-consent. These observations have to be interpreted with caution, as we cannot rule out potential center-level effects. However, given this limitation, our observations suggest that the choice of countries in which a trial should be run may modify the characteristics of the study population and hence may also influence the effects of the treatment under investigation.

There are statistical approaches to managing site differences in clinical trials, which broadly enclose the options of ignoring possible site effects, or of modeling them as either fixed effects or random effects. ${ }^{22}$ There is, however, no standard solution for this problem, but the best strategy for controlling site effects depends on the expected effects, including confounding and site-by-treatment interaction. In WAKE-UP, randomization is stratified by site in order to avoid imbalances between sites concerning treatment allocation, and site and country will be addressed as confounding factors in the final statistical analysis.

The time-critical nature of interventions, the high prevalence of incapacity in acute stroke, and the demonstrable effect of proxy consent on trial conduct and populations call for considering approaches that might expedite proxy consent procedures for stroke clinical research, as has been considered in other emergency conditions. ${ }^{23,24}$ The Council for International Organizations of Medical Sciences has recently proposed new international ethical guidelines for 
health-related research involving humans that, among other issues, address research in emergency settings and in patients incapable of providing informed consent. ${ }^{25}$ There is an urgent need for clearer, more homogeneous, and more pragmatic regulations for enrollment of incapable patients into clinical trials. The opinions of stroke patients and caregivers should also be considered. In prospective interview studies, a majority of patients agreed to participate in acute stroke trials without conventional informed consent. ${ }^{26,27}$ The concept of exception from informed consent for clinical research in neurologic emergency conditions like stroke was also generally accepted and deemed appropriate given approval of institutional review boards in a qualitative study of several focus groups including stroke patients, their families, and healthy young individuals. ${ }^{28}$

In a large population of patients enrolled in a randomized controlled trial of IV thrombolysis in stroke,

\section{Comment:}

\section{Capacity, consent, and country in acute stroke research}

In this study, Thomalla et al. ${ }^{1}$ compare baseline characteristics of participants providing informed consent with those enrolled by surrogate permission (legal guardian, next of kin, investigator and independent physician, or just investigator) from the first 1,005 participants enrolled in WAKE-UP, a multinational European clinical trial of MRI-based thrombolysis in stroke patients with unknown time of onset. In accordance with European and national regulations, multiple options for obtaining consent were made available.

The topic is important-kudos to the investigators for capturing and analyzing data related to manner of consent. Remarkably, 1,005 of 1,039 enrolled participants had this information available. Indeed, an international consortium of stroke researchers have recommended recording manner of consent as a core element in genetic studies to allow explicit consideration of consent status. ${ }^{2}$

This study confirms prior findings that participants enrolled by surrogate permission have more severe strokes and also shows more frequent aphasia and reduced levels of consciousness. While these latter novel findings are not necessarily surprising, they underscore the potential for bias if proxy consent is not allowed.

Interestingly, the investigators uncovered substantial variation in the manner of consent across the countries involved. They can only speculate about this surprising finding. Further, a smaller proportion of participants overall was enrolled by proxy consent than in other studies of acute stroke, suggesting discomfort with some of these mechanisms. Further research identifying when and why various forms of proxy consent are or are not allowed, and when and why they are not utilized even when legally permissible, could help future investigators plan appropriately when designing studies in acute stroke and other conditions that have potential to impair an individual's ability to provide informed consent for research participation.

1. Thomalla G, Boutitie F, Fiebach JB, et al. Effect of informed consent on patient characteristics in a stroke thrombolysis trial. Neurology 2017;89:1400-1407.

2. Majersik JJ, Cole JW, Golledge J, et al; International Stroke Genetics Consortium. Recommendations from the International Stroke Genetics Consortium, part 1: standardized phenotypic data collection. Stroke 2015;46:279-284.

3. Chen DT. Why surrogate consent is important: a role for data in refining ethics policy and practice. Neurology 2008;71:1562-1563.

Donna T. Chen, MD, MPH

Bradford B. Worrall, MD, MSC

From the Center for Biomedical Ethics and Humanities (D.T.C.) and Departments of Neurobehavioral Sciences (D.T.C.), Public Health Sciences (D.T.C., B.B.W.), and Neurology (B.B.W.), University of Virginia School of Medicine, Charlottesville.

Disclosures: D.T.C. reports no disclosures. B.B.W. is Deputy Editor of Neurology. Go to Neurology.org for full disclosures. we demonstrate that the manner of informed consent affects the clinical characteristics of patients. In addition, the manner of informed consent differed significantly among countries. These findings illustrate the importance of identifying strategies for the inclusion of incapable patients in acute stroke trials. As of yet, reperfusion treatment is the only effective treatment strategy for acute stroke, and it is still only available for a limited subgroup of stroke patients. Further clinical trials improving treatment of acute stroke and testing new treatment approaches are urgently needed. Currently, differences in national regulations and diverging practice to informed consent may hamper trial success. More harmonized interpretation and implementation of international regulations into national practice is required to enable comparable practice including all different manners of consent in an emergency setting among different countries.

\section{AUTHOR CONTRIBUTIONS}

Götz Thomalla: study concept and design, acquisition of data, analysis and interpretation of data, study supervision, drafting/revising the manuscript for content. Florent Boutitie: analysis and interpretation of data, drafting/revising the manuscript for content. Jochen B. Fiebach: study concept and design, acquisition of data, drafting/revising the manuscript for content. Claus Z. Simonsen: study concept and design, acquisition of data, drafting/revising the manuscript for content. Norbert Nighoghossian: study concept and design, acquisition of data, drafting/revising the manuscript for content. Salvador Pedraza: study concept and design, acquisition of data, drafting/revising the manuscript for content. Robin Lemmens: acquisition of data, drafting/revising the manuscript for content. Pascal Roy: analysis and interpretation of data, study supervision. Keith W. Muir: study concept and design, acquisition of data, drafting/ revising the manuscript for content. Chistoph Heesen: drafting/revising the manuscript for content. Martin Ebinger: study concept and design, acquisition of data, drafting/revising the manuscript for content. Ian Ford: drafting/revising the manuscript for content. Bastian Cheng: study concept and design, acquisition of data. Tae-Hee Cho: acquisition of data, drafting/revising the manuscript for content. Josep Puig: acquisition of data, drafting/revising the manuscript for content. Vincent Thijs: study concept and design, acquisition of data, drafting/revising the manuscript for content. Matthias Endres: acquisition of data, study supervision, drafting/revising the manuscript for content. Jens Fiehler: study concept and design, acquisition of data, drafting/revising the manuscript for content. Christian Gerloff: study concept and design, analysis and interpretation of data, study supervision, drafting/revising the manuscript for content.

\section{STUDY FUNDING}

WAKE-UP receives funding from the European Union Seventh Framework Programme (FP7/2007-2013) under grant agreement no. 278276 (WAKE-UP)

\section{DISCLOSURE}

G. Thomalla received fees as a consultant or lecture fees from Acandis, Bayer Vital, Bristol-Myers Squibb/Pfizer, Boehringer Ingelheim, Daichii Sankyo, GlaxoSmithKline, and Stryker. F. Boutitie reports no disclosures relevant to the manuscript. J. Fiebach received consulting, lecture, and advisory board fees from Perceptive, BioClinica, Boehringer Ingelheim, Cerevast, Brainomix, and Lundbeck. C. Simonsen received lecture fees from Boehringer-Ingelheim. N. Nighoghossian reports no disclosures relevant to the manuscript. S. Pedraza received fees as a board member, consultant, or lecturer from Lundbeck and Synarc. R. Lemmens is a senior clinical investigator of FWO Flanders. P. Roy reports no disclosures relevant to the manuscript. K. Muir has received honoraria for speaking from Boehringer Ingelheim and Bayer and has received consultancy 
fees from ReNeuron Ltd. C. Heesen received grants or speaker honoraria from Bayer, Biogen, Genzyme, and Novartis. M. Ebinger, I. Ford, B. Cheng, T. Cho, and J. Puig report no disclosures relevant to the manuscript. V. Thijs received honoraria from Astra Zeneca, Bayer, Bristol-Myers Squibb, Boehringer-Ingelheim, and Pfizer for participation in advisory board meetings. M. Endres received fees from Amgen, Bayer, Boehringer Ingelheim, Bristol-Myers Squibb, Ever, Glaxo Smith Kline, MSD, Pfizer, Novartis, and Sanofi. J. Fiehler received fees as a consultant or lecture fees from Codman, Covidien, Siemens, and Stryker. C. Gerloff received fees as a consultant or lecture fees from Bayer Vital, Boehringer Ingelheim, EBS Technologies, Glaxo Smith Kline, Lundbeck, Pfizer, Sanofi Aventis, Silk Road Medical, and UCB. Go to Neurology.org for full disclosures.

Received December 21, 2016. Accepted in final form June 19, 2017.

\section{REFERENCES}

1. World Medical Association Declaration of Helsinki: ethical principles for medical research involving human subjects. JAMA 2013;310:2191-2194.

2. Lees KR, Emberson J, Blackwell L, et al. Effects of alteplase for acute stroke on the distribution of functional outcomes: a pooled analysis of 9 trials. Stroke 2016;47: 2373-2379.

3. Ribo M, Molina CA, Cobo E, et al. Association between time to reperfusion and outcome is primarily driven by the time from imaging to reperfusion. Stroke 2016;47: 999-1004.

4. Demarquay G, Derex L, Nighoghossian N, et al. Ethical issues of informed consent in acute stroke: analysis of the modalities of consent in 56 patients enrolled in urgent therapeutic trials. Cerebrovasc Dis 2005;19:65-68.

5. Mangset M, Forde R, Nessa J, Berge E, Wyller TB. I don't like that, it's tricking people too much...: acute informed consent to participation in a trial of thrombolysis for stroke. J Med Ethics 2008;34:751-756.

6. Bateman BT, Meyers PM, Schumacher HC, Mangla S, Pile-Spellman J. Conducting stroke research with an exception from the requirement for informed consent. Stroke 2003;34:1317-1323.

7. Slyter H. Ethical challenges in stroke research. Stroke 1998;29:1725-1729.

8. Brady MC, Fredrick A, Williams B. People with aphasia: capacity to consent, research participation and intervention inequalities. Int J Stroke 2013;8:193-196.

9. Flaherty ML, Karlawish J, Khoury JC, Kleindorfer D, Woo D, Broderick JP. How important is surrogate consent for stroke research? Neurology 2008;71:1566-1571.

10. Kane I, Lindley R, Lewis S, Sandercock P. Impact of stroke syndrome and stroke severity on the process of consent in the Third International Stroke Trial. Cerebrovasc Dis 2006;21:348-352.

11. Thomalla G, Fiebach JB, Ostergaard L, et al. A multicenter, randomized, double-blind, placebo-controlled trial to test efficacy and safety of magnetic resonance imagingbased thrombolysis in wake-up stroke (WAKE-UP). Int J Stroke 2014;9:829-836.

12. Thomalla G, Cheng B, Ebinger M, et al. DWI-FLAIR mismatch for the identification of patients with acute ischaemic stroke within $4.5 \mathrm{~h}$ of symptom onset (PREFLAIR): a multicentre observational study. Lancet Neurol 2011;10:978-986.
13. Brott T, Adams HP Jr, Olinger CP, et al. Measurements of acute cerebral infarction: a clinical examination scale. Stroke 1989;20:864-870.

14. Dani KA, McCormick MT, Muir KW. Brain lesion volume and capacity for consent in stroke trials: potential regulatory barriers to the use of surrogate markers. Stroke 2008;39:2336-2340.

15. Mendyk AM, Labreuche J, Henon $\mathrm{H}$, et al. Which factors influence the resort to surrogate consent in stroke trials, and what are the patient outcomes in this context? BMC Med Ethics 2015;16:26.

16. Smith J, Forster A, Young J. Cochrane review: information provision for stroke patients and their caregivers. Clin Rehabil 2009;23:195-206.

17. Hotter B, Jegzentis K, Steinbrink J, et al. Impact of selection criteria on recruitment in an interventional stroke trial. Cerebrovasc Dis 2013;36:344-350.

18. Leira EC, Kaldjian LC, Ludwig BR, et al. Lack of international consensus on ethical aspects of acute stroke trials. J Stroke Cerebrovasc Dis 2012;21:200-204.

19. Directive 2001/20/EC of the European Parliament and of the Council of 4 April 2001 on the approximation of the laws, regulations and administrative provisions of the Member States relating to the implementation of good clinical practice in the conduct of clinical trials on medicinal products for human use. OJ 2001;L121: 34-44.

20. Lemaire F, Bion J, Blanco J, et al. The European Union Directive on Clinical Research: present status of implementation in EU member states' legislations with regard to the incompetent patient. Intens Care Med 2005;31: 476-479.

21. Yusuf S, Wittes J. Interpreting geographic variations in results of randomized, controlled trials. N Engl J Med 2016;375:2263-2271.

22. Feaster DJ, Mikulich-Gilbertson S, Brincks AM. Modeling site effects in the design and analysis of multi-site trials. Am J Drug Alcohol Abuse 2011;37:383-391.

23. Iwanowski P, Budaj A, Czlonkowska A, et al. Informed consent for clinical trials in acute coronary syndromes and stroke following the European Clinical Trials Directive: investigators' experiences and attitudes. Trials 2008;9:45.

24. Qureshi AI, Gilani S, Adil MM, et al. Pattern of informed consent acquisition in patients undergoing emergent endovascular treatment for acute ischemic stroke. J Vasc Interv Neurol 2014;7:21-25.

25. Sciences CfIOoM. International Ethical Guidelines for Health-Related Research Involving Humans. Geneva: Council for International Organizations of Medical Sciences; 2016.

26. Kleindorfer D, Lindsell CJ, Alwell K, et al. Ischemic stroke survivors' opinion regarding research utilizing exception from informed consent. Cerebrovasc Dis 2011;32:321-326.

27. Goldstein JN, Espinola JA, Fisher J, Pallin DJ, Camargo CA. Public opinion of a stroke clinical trial using exception from informed consent. Int J Emerg Med 2010;3:385-389.

28. Kasner SE, Baren JM, Le Roux PD, et al. Community views on neurologic emergency treatment trials. Ann Emerg Med 2011;57:346-354 e6. 


\section{Neurology}

Effect of informed consent on patient characteristics in a stroke thrombolysis trial Götz Thomalla, Florent Boutitie, Jochen B. Fiebach, et al.

Neurology 2017;89;1400-1407 Published Online before print August 25, 2017

DOI 10.1212/WNL.0000000000004414

This information is current as of August 25, 2017

Neurology ${ }^{\circledR}$ is the official journal of the American Academy of Neurology. Published continuously since 1951, it is now a weekly with 48 issues per year. Copyright Copyright $@ 2017$ The Author(s). Published by Wolters Kluwer Health, Inc. on behalf of the American Academy of Neurology.. All rights reserved. Print ISSN: 0028-3878. Online ISSN: 1526-632X.

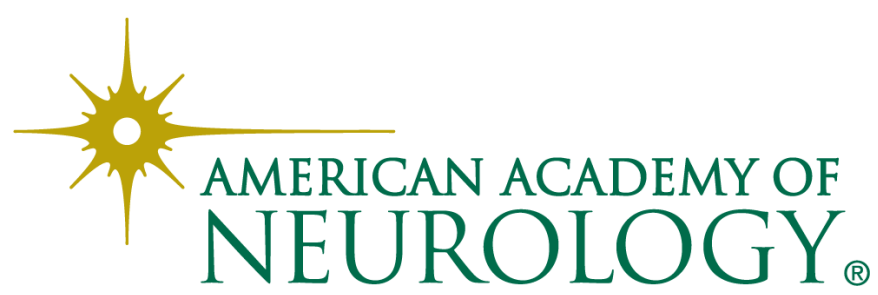




\section{Updated Information \& Services}

\section{Supplementary Material}

References

Citations

Subspecialty Collections

Permissions \& Licensing

Reprints including high resolution figures, can be found at: http://n.neurology.org/content/89/13/1400.full

Supplementary material can be found at: http://n.neurology.org/content/suppl/2017/08/25/WNL.0000000000004 414.DC1

This article cites 26 articles, 8 of which you can access for free at: http://n.neurology.org/content/89/13/1400.full\#ref-list-1

This article has been cited by 2 HighWire-hosted articles: http://n.neurology.org/content/89/13/1400.full\#\#otherarticles

This article, along with others on similar topics, appears in the following collection(s):

All Cerebrovascular disease/Stroke http://n.neurology.org/cgi/collection/all_cerebrovascular_disease_strok e

All Clinical trials

http://n.neurology.org/cgi/collection/all_clinical_trials

All Ethics in Neurology/Legal issues

http://n.neurology.org/cgi/collection/all_ethics_in_neurology_legal_iss ues

Clinical trials Methodology/study design

http://n.neurology.org/cgi/collection/clinical_trials_methodology_study design_

MRI

http://n.neurology.org/cgi/collection/mri

Information about reproducing this article in parts (figures,tables) or in its entirety can be found online at:

http://www.neurology.org/about/about_the_journal\#permissions

Information about ordering reprints can be found online:

http://n.neurology.org/subscribers/advertise

Neurology ${ }^{\circledR}$ is the official journal of the American Academy of Neurology. Published continuously since 1951, it is now a weekly with 48 issues per year. Copyright Copyright ( 2017 The Author(s). Published by Wolters Kluwer Health, Inc. on behalf of the American Academy of Neurology.. All rights reserved. Print ISSN: 0028-3878. Online ISSN: 1526-632X.

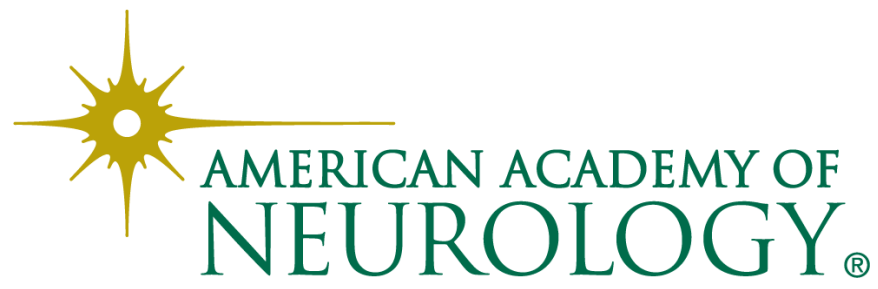

